\title{
The Mode of Textual Existence in Communicative Narratology
}

\author{
Wang Weiyan \\ Associate Professor, College of Liberal Arts, Xinyang Normal University, \\ Xinyang, China \\ wangweiyo4@163.com
}

\begin{abstract}
In communicative narratology, narrative texts are not cut and dry. Some of them indicate the mutual recognition between utterers and receivers, thus forming universal bidirectional texts; others rely on receivers' subsequent confirmation, forming unidirectional texts. Despite the different types, texts are essentially formulated via both sides of communication, which secondary narrativization pervades. Indeed, this secondary narrativization entails the process of 're-textualization', eventually forming a 'secondary text'. It remains, in most cases, a type of 'abstract' text, which will not become tangible until it is embodied in signs.
\end{abstract}

\section{Keywords}

communicative narratology - narrative text - universal bidirectional text re-textualization

In the study of classic and post-classic narratology, a narrative text is given as a fact whose reality is self-evident. However, from the perspective of the communicative narratology, whether a text is a communication is not determined by the text itself, but constituted by both the addressor and the addressee. There are thus new modes of existence for narrative texts, and the objective of this article is to study these new cases.

The certainty of the existence of texts remains almost always unchallenged in the narratology, for without an explicit boundary of texts, any formal study 
of them will be problematic. As for narrative stratification within a certain text, one must acknowledge that they denote the basic object of the study of narratology: 'the entire study of modern narratology is based on this theory of duplicity, so much so that it serves as one of the starting points of modern critical theories over the last century' (Zhao Y., 2013: 119, my translation). However, the situation of narrative texts grows more complicated as one observes it in the framework of 'general narratology'. According to Zhao Yiheng, there are two bottom lines for the definition of narration, which is the process of bidirectional construction: first, a certain subject incorporates all the character-participating events into a semiotic text; second, the receiver of the text should perceive it as embodying dimensions of both time and sense (2013: 7, my translation). The fundamental question is whether or not the boundary of such a text be explicit. In other words, is it true that both the textual writer and the receiver face identical texts? This essay article will endeavour to discuss the mode of textual existence in communicative narratology.

\section{Communication as the Way Narrative Texts Exist}

Charles Sanders Peirce offered the following definition of the sign, object, and interpretant:

I define a Sign as anything which on the one hand is so determined by an Object and on the other hand so determines an idea in a person's mind, that this latter determination, which I term the Interpretant of the sign, is thereby mediately determined by that Object. A sign, therefore, has a triadic relation to its Object and to its Interpretant.

PEIRCE, 2O14: 31

This so-called 'triadic relation' is obviously a bidirectional relation among a sign, its object and interpretant. This assertion actually indicates communication, in which any semiotic text cannot but consist. In other words, communication functions as the way semiotic texts exist, from which narrative texts cannot be exempt. Peirce exemplifies the conditions of communication as follows:

1. There must be an utterer and interpreter.

2. There must be something transmitted between utterer and interpreter.

3. What is transmitted between utterer and interpreter must be something that is capable of establishing common interpretants in both utterer and interpreter. (Liszka, 1996: 89) 
Any sign that particulates in the process of communication should be regarded as carrying intentions of the utterer, who harbours a certain 'expectation for interpretation', namely, that which expects the interpreter to interpret in accordance with the utterer's intentions. Should this idealized situation be granted, then one can be assured that the so-called 'common interpretants' will be generated: Communication cannot be generated unless the utterer could produce an intended interpretant and the interpreter could produce an effectual interpretant. However, it is necessary to point out that the utterer's intention cannot completely conform with the interpreter's interpretation, and in most cases, they are overlapping. For example, the quantity of information between the utterer and the interpreter can be different. According to Peirce's theory of 'information',

semiotic information is the quantity of interpretants, which depends upon various degrees of interpretation symbol-users make in accordance with their knowledge status. Therefore, during the specific process of transmission, interpreters can apply different cognitive strategies on the basis of various symbolic forms.

ZHAO X., 2O16: 164

Still, it is certain that any semiotic text consists in communication, which is the very way any semiotic text exists. Any text that refuses to communicate does not exist because signs denote the absence of meaning. The basic function of signs is to replace 'objects' and to pass on meaning, which also works well for narrative texts; hence, communication is also the fundamental way in which they exist.

Saussurian linguistics tend to enclose the meaning within textual boundaries. By doing so, Saussure cuts off the communicative chain of a given text as he regards the relation between the signifier and the signified as the basic mode of signification. Also, such relation is arbitrary at first and assumes its legal status once settled. For example, the signifier 'tree' is arbitrarily connected with the 'tree' in the real world, but this connection, once confirmed, becomes conventional and resists change. And it seems that this relation has very little to do with both utterers and interpreters since that referential structure of 'tree' is fixed regardless of their will. And the same principle can be applied to a many binary relations, such as parole and langue as well as surface and deep structures. This is in fact the basic idea of structuralism. Nevertheless, literature is characterized by its evocative and aesthetic drives whose deprivation erases its charm. What Saussurian binary structure neglects is that meaning can be changed in the process of interpretation. 
Given the backdrop of the narrative turn and the theoretical framework of general narratology, numerous narrative phenomena and texts provide new directions for the study of narratology. Communication becomes a crucial quality in news narration, forensic narration, educational narration, ludic narration (including sports narration), performative narration, and so on. Some narrative texts cannot be said to exist unless communication exists. Any narrative text consists in communication and texts are always dynamically constructed. Therefore, as far as general narratology is concerned, returning to Peirce reveals something crucial. As Zhao Yiheng realizes:

Peirce's triadic relation among signs, objects and interpretants evacuates signs from the construction of the signifier/signified.... Peirce is not satisfied with the assertion that meaning belongs to individuals. Rather, he regards semiotics as a set of sociological theories that can promote interpersonal relationship. What concerns Peirce most is the interpretation of signs, which is not merely an individual behavior. He believes that once people start pursing meaning, they cannot choose but to enter into interpersonal relationship. Thus, semiotic meaning must be a type of communicative meaning.

ZHAO Y., 2014: 7-9, my translation

Clearly semiotic texts, including narrative texts, reside in communicative relations, especially for those texts which have been formulated in the process of communication, and 'for Peirce, thought is always an I-you conversation' (Wiley, 1994: 24). This 'I-you' conversation is the process from the present to the future, whose uncertainty renders meaning relentlessly constructed in a dynamic way.

In communicative narratology one must take into consideration the conditions by which narrative texts come into existence. Among all the sides which participate in communication, neither the creator nor the receiver alone is entitled to decide whether the text they are dealing with can be regarded as a narrative one. Nevertheless, the creator is allowed to dwell in an 'unconscious' mode of narration, which is bound to happen within the framework of 'general narratology'. Take sports narration as an example: although neither sportsmen nor participants are conscious of narration itself, they are still engaged in a 
series of competitive activities within the boundaries of sportsmanship, which harbours basic narrative qualities. And one may even provide new outlooks for the study of sport from the perspective of narratology. Meanwhile, given the fact of 'medium sports', it has long been customary for professionals to interpret competitive sports in a narrative way. Neglecting this, one will turn a blind eye to one's important field in the study of narratology. Furthermore, other fields, such as education, medical system, history, and media, have all been enhanced in their research value due to the introduction of narratology as a new perspective. One can thus perceive that no matter how imperative theoretical induction is with regard to the study of general narratology, the redefinition of narration itself merits more significance, and to achieve this, one must categorize as many forms of narrative texts as possible into the study of narratology. Certainly, this goal is far from the castle in the air; rather, it serves as both a recognition of the narrative qualities of human behaviours and a narratological response to the recent 'narrative turn'.

As far as the communicability of narration is concerned, despite its crucial position in all narrative texts, the degree to which its significance is required varies as narrative forms differ from one another. For example, narrative forms such as medical, media, sports, forensic, educational, ludic, oral-arts, and dramatic ones must rely on communication to actualize their textuality. Other narrative forms, such as literary and dream narratives, do not specifically represent communicability from the writer's perspective. In literary narrative, especially 'serious' literature, writers pursue artistic qualities and attach great importance to literary independence and creativity to the point where he or she sometimes would not hesitate to put the fluency of reading process into secondary position. For instance, the Russian formalist Viktor Shklovsky posited 'defamiliarization':

The technique of art is to make objects unfamiliar, to make forms difficult, to increase the difficulty and length of perception because the process of perception is an aesthetic end in itself and must be prolonged. Art is a way of experiencing the artfulness of an object; the object is not important.

SHKLOVSKY, 1965: 12

Still, the crucial position of communication in literature remains indisputable; rather, literature leads communicability to the independence and creativity it longs for. Similarly, different literary forms require various degrees of communicability. As far as popular fiction is concerned, its tendency towards kitsch 
demands that it should win over readers and assume a larger proportion of the market share. It is thus of crucial importance for popular fiction to formulate a desirable communicative relation with a wider range of readers.

Due to the elusiveness of literary communication, some scholars believe that literature is non-communicative. They even deem that the less receivers understand writers, the better literary works will be. For example, Paul Valéry believed that 'producers and consumers are mutually independent, and that they do not get into what they think or need, which is, for the effect of a certain piece of artistic work, of crucial importance' (qtd. in Wellek, 1983: 30). It should be pointed out, however, that Valéry's viewpoint lacks the basis of shared experience, which obstructs the process of communication and renders it invalid. Indeed, shared experience and cultural convention serve as the bottom line to which literary independence and creativity are connected. Thus new experience will be replicated and inherited within this spiral mode of original outlook, promoting the accumulation and renewal of experience.

Other scholars also discuss the 'non-communicability' of literature. Jan Mukařovský, a leading member of the Prague Linguistic Circle, differentiates journals, especially those containing political essays and poetry, in terms of their communicability. He points out that in journalistic style, 'it is always subordinate to communication: its purpose is to attract reader's (listener's) attention more closely to the subject matter expressed by the foregrounded means of expression', whereas 'in poetic language foregrounding achieves maximum intensity to the extent of pushing communication into the background as the objective of expression and of being used for its own sake; it is not used in the service of communication, but in order to place in the foreground the act of expression, the act of speech itself' (Mukařovský, 1989: 6). In fact, Mukařovský would rather transform the object of communication to literary expression itself than assert that poetry 'is not used in the service of communication'.

Similarly, the leading light of the New Criticism, I. A. Richards, believed that artists cannot regard communication as the core issue of artistic creation. One could bring about disastrous artistic works by overestimating communication: 'The dissipation of attention which would be involved if he considered the communicative side as a separate issue would be fatal in most serious work' (Richards, 2001: 22). In fact, the negligence of communication does not mean that artistic works are non-communicative. On the contrary,

this conscious neglect of communication does not in the least diminish the importance of the communicative aspect. It would only do so if we were prepared to admit that only our conscious activities matter. The 
very process of getting the work 'right' has itself, so far as the artist is normal, immense communicative consequences.

RICHARDS, 2OO1: 22

Thus one can see that Mukařovský and Richards both share the basic view. Namely, although communication is not the foremost component artists pursue while creating arts, it still marks the character of artistic works. 'How far desire actually to communicate, as distinguished from desire to produce something with communicative efficacy (however disguised), is an unconscious motive in the artist' (Richards, 2001: 23). Hereby one should distinguish the uniqueness of artistic creation from the communicability of artistic works; that is to say, artistic communicability and its validity rely on the pursuit of the artistic expression of independence and creativity. Richards again:

In any case it is certain that no mere careful study of communicative possibilities, together with any desire to communicate, however intense, is ever sufficient without close natural correspondence between the poet's impulses and possible impulses in his reader. All supremely successful communication involves this correspondence, and no planning can take its place. Nor is the deliberate conscious attempt directed to communication so successful as the unconscious indirect method.

Ibid., 24

While discussing Ann Banfield's works, Manfred Jahn clarifies their narrative non-communicability by pointing out those 'unspeakable sentences' in them.

There are sentences which express something without at the same time communicating anything, in other words, that expressing something is an autonomous function of language; whereas the literary theorist may be brought to reconsider his position on traditional notions such as point of view, the mediatedness of narrative texts, and dual voice interpretations.

JAHN, 1983: 23

Jahn differentiates linguistic communicability from narrative noncommunicability in literary theories and claims that 'narration consists of unspeakable, non-communicated sentences, even if there is a speaker (e.g. a first person narrator)' (ibid.). In other words, narratology and linguistics focus on different issues. The former attaches more importance to the implications and functions behind languages, whereas the latter concentrates on the communication brought by language itself. From another perspective, 
the communicability of narrative texts more often than not results from the deep structure behind the surface structure. The signifier does not cover all the aspects of narrative communicability; rather, it is the signified that points to the meaning of communication.

Therefore, the so-called 'literary non-communicability' does not prove that literature is lacking in communicability. Rather, literary communicability is unique in comparison with other types of speech in that it lies in the very quality of independence and creativity which literature pursues. As Lotman points out,

art is one of the ways of communication. Indisputably, it creates a bond between the sender and receiver (under certain circumstances both functions may be combined in one person, as in the case where a man conversing with himself is at once speaker and listener, but this does not alter matters).

2003: 9

Thus literary communicability is not arranged; it stands for its own quality. 'Communication of the work lies not in the fact that it has become communicable, through reading, to a reader. The work is itself communication' (Blanchot, 2003: 201). From the perspective of communication, there are two ways for narrative texts to exist.

First, as unidirectional texts, by which both textual creators and receivers can construct narrative texts on their own. In other words, creators could regard whatever they create as narrative texts and interpret them in a unique way, not taking into consideration whether or not receivers would agree with them; similarly, receivers could interpret a certain text as a narrative one, such as athletics, regardless of the creator's attitude towards it.

There is, however, a problem facing unidirectional texts: namely, once the text enters into the channel of communication, its validity (usually achieved by narrative texts) cannot be guaranteed. In other words, unidirectional texts cannot choose but to risk communicative inadequacy. Unidirectional texts from writers' perspective face communicative dislocation; namely, receivers refuse to regard those texts as narrative ones. There might be two reasons for this refusal: first, writers in their self-reflective minds deliberately forestall the situation once those texts enter the channel of communication; second, writers lack knowledge concerning narrative genres and thus breach genre conventions or formal restrictions. Unidirectional texts from receivers' perspective face affective misunderstanding (both deliberate and unintentional). And there are also two reasons for that: first, receivers assume a specific position in order to steer their interpretations from the normal track on purpose; second, 
receivers incur difficulties in terms of comprehension due to their deficiency of related knowledge and experience.

The second way for narrative texts to exist is as universal bidirectional texts, by which creators conform to general narrative principles and receivers interpret the texts accordingly. Both creators and receivers bring about textual narrativity; meanwhile, the expected communicative validity can be fulfilled. This type of texts risks much less than the first type does, only at the cost of a relatively banal communicative outcome. Besides, due to the insistence on narrative rules, textual creativity can be diminished.

Another problem facing bidirectional texts is the issue of the bidirectional construction of narrative texts. It is not important whether or not creators create narrative texts on purpose, or receivers interpret a given text as a narrative one: so long as narrative texts are brought into the process of communication, they will always become a bidirectional structure. From creation to communication, from original narrative to secondary narrative, texts are constantly constructed. Bidirectional texts are so prevalent that any narrative text can be called a universal bidirectional text.

\section{Communicative Narrative and 'Re-textualization'}

It is acknowledged that the stage of secondary narrativization produces secondary narrative texts. If receivers cannot successfully construct secondary texts, it might be a hint that such a stage has encountered some unexpected problems. Zhao Yiheng has conducted a detailed study on secondary narrativization. He categorizes it into four types: corresponding, reductive, compromising, and creative, among which there lies a progressive process. 'Corresponding' is not complicated. It requires receivers to understand the texts accordingly without allowing them to interpret on their own. 'Reductive' means to 'seek out intelligibility in accordance with cultural convention', and 'the standard of intelligibility is a series of cognitive rules collected and developed from daily experience, either intentionally or accidentally' (Zhao Y., 2013: 109, my translation). 'Compromising' can be applied to those narrative texts that have a confusing plot arrangement, in which receivers have to seek secondary narrativization to restore narrative order. However, when the textual causality becomes irreversibly perplexing, so much so that receivers find it hard to tolerate it, and that they have almost reached the threshold of renunciation,

creative secondary narrativization becomes the most troublesome task in that it pushes secondary narrator's endurance and morality headlong 
to the extreme. Once receivers or interpretive communities cannot bear it any longer, they will give up interpretation, which brings about the forcible interruption of communication.

ZHAO Y., 2O13: 113, my translation

Clearly, these four categories are established in the light of the degree of textual 'intelligibility'.

The author of this article believes that the four categories of secondary narrativization are not a set of static legal procedures but rather delineate different conditions of acceptance by various receivers. In other words, the condition of secondary narrativization varies as receivers' reading capability differs. For those who rank low in the capability of interpretation, some essentially simple narrative texts could produce tremendous problems in terms of understanding, whereas those who can interpret quite well would not encounter such a dilemma. Therefore, those four categories are aimed at different types of receivers. At the same time, as for narrative texts, perhaps it is also correct that the intensity of textual narrativity (or that of intelligibility) is not equally distributed throughout the entire text. Secondary narrativization composes and adjusts certain parts of the original text, providing diversified ways of textual narration. While narration is taking place, the degree of intelligibility (or nonintelligibility) of a certain narrative text becomes heterogeneous. Therefore, during the process of partial interpretation, receivers tend to adopt different levels of secondary narrativization. Against the backdrop of the modern multimedia narrative, secondary narrativization resembles the readjustment of intermediary order, which symbolizes the process from signs to meaning and from meaning to experience.

Secondary narrativization allows the meaning of narrative texts to be rearranged and disseminated. The human ability of secondary narrativization changes with time, which provides the perspective for the construction of narrative experience. Here comes an important question: since narrative texts are not the final status of meaning, nor are they the ultimate material to which meaning is affiliated, is it correct that secondary narrative serves as the eventual stage of textual existence? This author would answer in the negative. The original text functions as the medium of communicative narration, and it is communication that reconstructs the order of experience. By secondary narrativization, no matter how it is conducted, receivers can always re-establish their order of experience. Furthermore, the causality and logic-value system (including ethics and ideology) are not equally distributed in narrative texts. Different methods of secondary narrativization are constantly introduced to the original text, reconstructing its logical experience. In doing so, secondary 
narrativization becomes both a method and a process, but it shall never become the final status of communicative narration. Instead it is re-textualization that accomplishes this final status. Both original texts and secondary narrativization serve as the means by which experience is constructed. Both sides of communication transform experience into signs according to their own understanding. Writers, out of a certain purpose, embody experience in signs and materialize them in the form of texts, which receivers, according to their comprehension, re-textualize and reconstruct. This process of reconstruction entails textual 'naturalization', which, to some extent, redresses the transformed and symbolized experience until it becomes intelligible (which is highly individualized and thus may not be suitable for everyone) for receivers who eventually formulate 'recipient texts', or secondary texts.

Due to the complexity of readership, any narrative text has numerous ways to be decoded and generated into meaning. All narrative texts that have been produced go through the process of secondary narrativization. Each reader produces his or her own version of interpretation by the unique way of amalgamating all the elements that will assist it. Therefore, each reader produces an individualized 'secondary text', which resembles Peirce's 'interpretant':

The sign that is transmitted can establish an interpretant in the interpreter somewhat similar to its establishment in the utterer. In other words, communication occurs when the utterer and interpreter can be 'welded' by the transmitted sign.

LISZKA, 1996: 91

By the word 'welded' Liszka refers to what Peirce calls the 'common interpretants'. In communicative narrative, both participants do not necessarily share exactly the same narrative text; rather, they produce their texts respectively on the basis of the original. Still, they must share something in common, which serves as the foundation of communication. Hence, as far as communicative narratology is concerned, narrative texts reach an abstract stage that is located on the middle ground between participants who have engaged in communication.

The dissemination of signs aims to acquire meaning eventually. 'Men live in the world of meaning. Things exist in themselves and they do not subject to human will; the world of meaning, however, is expanded from the confrontation between things and human will' (Zhao Y., 2017: 2, my translation). The goal of secondary narrativization is to construct meaningful texts, and to acquire meaning one must first establish a textual order, either physical or mental. In other words, establishing narrative order is the way one acquires meaning. It 
is narrative order that reaches out to experience, which is further connected to meaning itself. By this process, the chain of meaning is finally produced. That is the reason why a narrative text becomes difficult to understand when its physical or mental order is disturbed. And if receivers endeavour to make sense of the text, they will have to restore the order according to their own experience. In fact, this process of restoration functions as a bridge that leads one to meaning. Without this process, receivers can fail to connect themselves with the text, which will result in the failure of the construction of meaning.

Semantic deviation exists in the process of re-textualization. One of the features of language is ubiquity, which can be perceived in a certain text or even a sentence. However, as far as the meaning of those linguistic sections is concerned, each individual may have his or her own specific point of view, despite the fact that people can share the same cultural tradition. For example, everyone understands the basic connotation and denotation of the word 'eating', but people do not necessarily agree on every detail that word indicates, such as what to eat, when to eat, or how to eat. Therefore, it is clear that bidirectional communication produces meaning. Firstly, the utterer harbours an original intention or direction of meaning. Besides, he believes that both the receiver and he will understand the message in a similar way, because the self-reflexive feature of expression urges him to take it as the basis of communication so that others are able to understand the way he understands. As for the receiver, he or she follows their own personal understanding based on a general intention. Despite a certain degree of deviation from the axis of intention, the receiver would not cross the boundary. Indeed, these phenomena serve as the basis of cultural continuity and development, and both of them can become problematic if such basic intention and a proper amount of deviation disappear. Indeed, there are three modes of meaning: the basic, the deviated, and the communicative. The first comes from the utterer; the second originates with the receiver; the third is generated from the compromise or collaboration of both sides, which is also the dynamic expansion of textual meaning.

Meaning is always more than a form. Rather, it indicates cultural tradition. When discussing meaning, one must take into consideration the utterer's personal traits and the relevant cultural background. The meaning of some texts, such as written ones and those separating meaning from subjects, does not seem to have anything to do with the utterers. Nevertheless, if both utterers and meaning are present, such a case would no longer hold water. Still, personally speaking, the difference lies in the fact that in the first situation, the spiral mode of utterers' experience has been suspended for the time being, whereas in the second case this mode is activated and simultaneously reacts. Hence, meaning is always connected with utterers. In history some meaning 
has been deviating so much that it has surpassed 'basic meaning', drawing the communicative meaning much closer to deviation, and yet the shadowy basic meaning still lingers.

There are two cases for re-textualization, either from the creator or the receiver. So far as the first case is concerned, once the creator textualizes his or her objects of narration, such as sports, ludic, forensic, or medical narrative, the text itself must be re-textualized by the receiver. In most cases, people do not pay much attention to the creator's re-textualization, because this form of self-communication apparently affects others not a jot. In fact, this explanation is not persuasive. The real reason is that symbolic texts are intrinsically obscure. They are not as distinct as traffic lights; rather, even though the creator finishes the text, he will lower his status from authoritative creator to non-authoritative receiver, even to the point where the interpretation of other receivers can make him feel that he no longer retains the upper hand in front of his own works. Indeed, many writers feel unsatisfied with their immature works. Some of them shift their positions or revise their works after the fact of other receivers' re-textualization. For instance, Yang Mo revised The Song of Youth. Though in retrospect this revision was not altogether successful, and to some extent even a total failure, it shall still be excused, given the complicated situation of re-textualization at that time, which owes much less to a type of personal, academic, or aesthetic behavior than it does to the milieu in which the work emerged into the world. From this, it can be seen that no matter where the process of re-textualization comes from (either the writer or the receiver), it is never the result of a personal behavior. In fact, it must be greatly affected by cultural context in both positive and negative senses. Therefore, one can safely say that re-textualization is an impersonal phenomenon of cultural communication. Instead of being the study of literary forms, re-textualization is as a matter of fact a special type of cultural studies.

Re-textualization of narrative texts is a must for the study of communicative narratology. It is a generally meaningful textual system produced by the process of secondary narrativization, which is based on the original narrative text and is conducted by those who participate in the entirety of communication. Under the influence of contemporary contexts, re-textualization becomes less a personal than a collective behavior, governed by communities of interpretation. Both writers and receivers interpret the original texts through the process of re-textualization. Once completed, texts are no longer determined by writers; and once stripped away from the original context, neither are texts any longer authoritative. It is the process of re-textualization that determines the historical destiny of texts, and further influences the way writers are evaluated. Historically speaking, no one is authoritative in communication; there is 
hardly any stabilized initiator or receiver. Indeed, the exchange of identity can happen at any time, by which experience itself can gain growth.

\section{References}

Blanchot, Maurice (1955) Espace littéraire. Paris: Gallimard. Translated by Ann Smock as The Space of Literature (Lincoln: University of Nebraska Press).

Jahn, Manfred (1983) 'Narration as Non-communication: On Ann Banfield's Unspeakable Sentences'. Revised version of a paper originally published in Kölner Anglistische Papiere, 23. http://www.uni-koeln.de/ ameo2/jahn83.htm.

Liszka, James Jakób (1996) A General Introduction to the Semeiotic of Charles Sanders Peirce. Bloomington: Indiana University Press.

Lotman, Yuri (1971) Struktura khudozhestvennogo teksta. Providence: Brown University Press. Translated by Gail Lenhoff and Ronald Vroon as The Structure of the Artistic Text (Michigan: the University of Michigan).

Mukařovský, Jan (1987) 'Standard Language and Poetic Language'. http://www.doc88 .com/p-9428739216488.html.

Richards, I. A. (2001) Principles of Literary Criticism. New York: Routledge.

Shklovsky, Victor (1965) “Art as Technique." In Russian Formalist Criticism: Four Essays. Translated by Lee T. Lemon and Marion J. Reis (Lincoln: University of Nebraska Press).

Wiley, Norbert (1994) The Semiotic Self. Oxford: Polity Press.

Wellek, René (1983) Xifang sida pipingjia 西方四大批评家. Translated by Lin Xianghua. Shanghai: Fudan University Press.

Xingzhi, Zhao (2016) 'On the Concept of Information in Peircean Semiotics' (论皮尔 斯符号学中的信息概念, lunpiersifuhaoxuezhong de xinxigainian). Signs and Media 13, 164 .

Yiheng, Zhao (2013) A General Narratology (广义叙述学, guangyi xushuxue). Chengdu: Sichuan University Press.

Yiheng, Zhao (2014) 'Return to Peirce' (赵毅衡: 回到皮尔斯, hui-dao-pi-er-si). Signs and Media 9, 1-12.

Yiheng, Zhao (2017) 'Theories of Meaning, Semiotic Phenomenology and Philosophical Semiotics' (意义理论, 符号现象学, 哲学符号学, yiyililun fuhaoxianxiangxue zhexuefuhaoxue). Signs and Media 15, 1-9. 